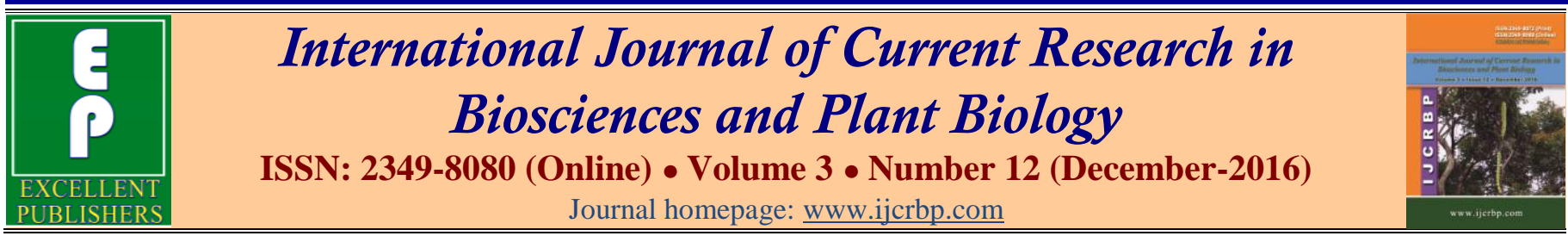

\title{
Effects of Chlorophyll Contents of Rice Bean Varieties/Lines as Influenced by Root-Knot Nematode, Meloidogyne incognita
}

\author{
Rashmita Behera, D.K. Nayak* and Rosalin Swain
}

Department of Nematology, College of Agriculture, Orissa University of Agriculture \& Technology, Bhubaneswar-751 oo3, Odisha, India

*Corresponding author.

\begin{abstract}
A study was undertaken with rice-bean (Vigna umbellata) varieties to compare the effects of root-knot nematode infection on the chlorophyll "a", "b" and "total contents of both susceptible and resistant varieties under infected and uninoculated control condition. Infection by the nematode caused decrease in chlorophyll content as 84.18 , $2.93,15.27$ and $30.79 \%$ in the varieties BBSR-19-2-1, BRB-26-1, BRB-25-1 and BRB-7-1 respectively. Similarly chlorophyll 'b' content was also reduced as $0.92 \%$, $0.23 \%, 14.62 \%$ and $53.75 \%$ in the varieties BBSR-19-2-1, BRB-26-1, BRB-25-1 and BRB-7-1 respectively. Due to infection of the nematode total chlorophyll content of rice bean varieties was reduced as $10.39,2.92,15.16$ and $38.75 \%$ in the varieties BBSR-19-2-1, BRB-26-1, BRB-25-1 and BRB-7-1 respectively. However, the decrease was non-significant in resistant varieties as compared to susceptible varieties. Decrease in chlorophyll content may possibly due to the alteration of host nutrition and physiology by nematode infection.
\end{abstract}

\section{Article Info}

Accepted: 10 November 2016

Available Online: 06 December 2016

\section{Keywords}

Chlorophyll contents

Meloidogyne incognita

Rice bean

Vigna umbellata

\section{Introduction}

Rice bean (Vigna umbellata) is an under exploited pulse crop having great potential for improvement as grain and fodder type. Previously this crop was known as Phaseolus calcaratus, a legume with slender twining vines and leaves. These are good source of protein, $\mathrm{Ca}$, $\mathrm{Fe}$, and vitamin $\mathrm{B}$. This is one of the promising pulses with high yield potential and optimum nutrition. It is commonly known as climbing bean, mountain bean, red bean, Xeruselum pea. In India it is known by different vernacular names such as moth bean, Rajmom, Satrangi and Mash.

The major causes of low productivity are the incidence of insects and diseases including plant parasitic nematodes. Plant parasitic nematode, Meloidogyne incognita alters the metabolic process of the host which are manifested in the form of cellular, physiological and biochemical changes occurring in the infected host. The root-knot nematodes cause measurable changes in the morphology and physiology of the host plants (Williamson and Gleason, 2003). As a result Meloidogyne infection amounts of chlorophyll pigment, protein and oil contents are being changed. Reduction in chlorophyll content of the infected plants has been reported by Vashishth et al. (1994), Poornima and Vadivelu (1998), Ramakrishna and Rajendran (1998) and Parveen et al. (2006), Nayak (2006), Pandey et al. (2016) in different crops. Melakeberhan et al. (1985) reported 
that total chlorophyll and chlorophyll- a content in Phaseolus vulgaris plants infected with different levels of $M$. incognita, decreased significantly with increased levels of infestation @ 3 weeks after inoculation (45 DAS). Vaishnav et al. (1985) observed that the chlorophyll a, b and total fractions decreased by 75.7 , 79.4 and $76.7 \%$ in comparison to control at 60 days after inoculation in peanut plants infected by $M$. arenaria.

Nayak (2006) reported chlorophyll 'a' content of infected leaves in case of Pusa Kranti varieties was reduced from $2.70 \mathrm{mg} / \mathrm{g}$ to $2.010 \mathrm{mg} / \mathrm{g}$. Similarly, in other varieties like Kantabaigan and Pusa Purple Long, chlorophyll 'a' content also reduced. Further, he reported that chlorophyll ' $b$ ' and total chlorophyll content was reduced in the infected leaves of brinjal varieties. In the present study, the effects of root-knot nematode infection on the chlorophyll "a","b" and "total contents of both susceptible and resistant varieties of rice-bean (Vigna umbellata) under infected and uninoculated control condition.

\section{Materials and methods}

\section{Chlorophyll estimation of leaf}

In order to understand the basis of nematode resistance four varieties/lines of rice bean were taken for observation. Out of four varieties 2 resistant varieties i.e., BRB-25-1, BRB-26-1 and two susceptible varieties i.e., BBSR-19-2-1 , BRB7-1 were procured from AICRP on Fodder Crops, OUAT, Bhubaneswar and were grown in earthen pots arranged in the green house of Nematology Department, C.A sterilized with formaldehyde solution
(1.0\%) and filled with autoclaved soil @ $15 \mathrm{lbs} / 20 \mathrm{~min}$. Pots were arranged on the green house benches in Complete Randomised Block Design with three replications according to the treatments. The water used for irrigation purpose was passed through a 500 mesh sieve before use. The soil to be filled in the pots was pulverized, mixed with NPK fertilizer@ $1 \mathrm{~kg} /$ pot. The surface sterilized seeds were sown @ 5 to 10 seeds per pot. Each variety was replicated thrice.

Watering was done regularly, 10 to 12 days after sowing; the plants were thinned keeping one seedling per pot. A small glass tube ( $2 \mathrm{~cm}$ long, $0.5 \mathrm{~cm}$ bore) was inserted into the soil near the base of each of the healthy seedlings. Three weeks after seedling emergence axenised nematodes were counted under a stereoscopic microscope and released into the holes after removal of the glass tube @ $1000 \mathrm{~J}_{2}$ per seedlings in $10 \mathrm{ml}$ sterile water. For chemical analysis two sets of plants were maintained, one for the uninoculated control (Healthy) and the other infected with the nematode. Each set was arranged on separate platforms in the green house in order to avoid cross infection.

One hundred fifty mg leaf portion of each treatment was cut from the composited leaves and were immersed in 50 $\mathrm{ml}$ of $80 \%$ acetone in a conical flask and kept in dark for $24 \mathrm{hrs}$ for extraction of chlorophyll from the leaf samples. Thereafter, the chlorophyll extracts were filtered through Whatman No.1 filter paper. Absorbance of the chlorophyll extract was measured at $645 \mathrm{~nm}$ and $663 \mathrm{~nm}$ using a colorimeter. The amount of chlorophyll$\mathrm{a}$, chlorophyll-b and total chlorophyll were calculated in $\mathrm{mg} / \mathrm{g}$ fresh weight according to the following equations.

i) Chlorophyll $-\mathrm{a}(\mathrm{mg} / \mathrm{g}$ fresh weight of leaf $)=12.7 \times(\mathrm{D}-663)-2.69 \times(\mathrm{D}-645) \times \frac{\mathrm{V}}{1000 \times \mathrm{W}}$

ii) Chlorophyll-b $(\mathrm{mg} / \mathrm{g}$ fresh weight of leaf $)=22.9 \times(\mathrm{D}-645)-4.68 \times(\mathrm{D}-663) \times \frac{\mathrm{V}}{1000 \times \mathrm{W}}$

iii) Total chlorophyll $(\mathrm{mg} / \mathrm{g}$ fresh wt. of leaf $)=20.2 \times(\mathrm{D}-645)+8.02 \times(\mathrm{D}-663) \times \frac{\mathrm{V}}{1000 \times \mathrm{W}}$

Where,

$\mathrm{D}-645=$ optical density at $645 \mathrm{~nm}$.

D-663 = optical density at $663 \mathrm{~nm}$.

$\mathrm{V}=$ final volume of $80 \%$ acetone chlorophyll extract in $\mathrm{ml}$.

$\mathrm{W}=$ Fresh weight in $\mathrm{g}$ of corresponding amount of fresh leaves used in the extraction of chlorophyll. 


\section{Results and discussion}

In the experiment from Table 1 , it was observed that due to infection of the nematode the chlorophyll ' $a$ ' content was reduced by $84.18 \%, 2.93 \%, 15.27 \%$ and30.79\% over control in varieties BBSR-19-2-1, BRB-26-1, BRB-25-1 and BRB-7-1 respectively. It is clearly known from Table 1 that the infection of the nematode, Meloidogyne incognita resulted in the reduction of chlorophyll ' $b$ ' content: $0.92 \%, 0.23 \%$, $14.62 \%$ and $53.75 \%$ over control in varieties BBSR-192-1, BRB-26-1, BRB-25-1 and BRB-7-1 respectively. Also, the total chlorophyll content was affected by $10.39 \%, 2.92 \%, 15.16 \%$ and $38.75 \%$ over control in varieties BBSR-19-2-1, BRB-26-1, BRB-25-1 and BRB-7-1 respectively.

During the investigation, decreased chlorophyll content of chlorophyll 'a', 'b' and total chlorophyll was noticed in the leaves of rice bean varieties. However, the decrease was non-significant in resistant varieties as compared to susceptible varieties. Similar results were also reported by Vaishnav et al. (1985) and Tyagi and Alam (1990). Decrease in chlorophyll content may possibly due to the alteration of host nutrition and physiology by nematode infection. Root-knot nematode infection leads to the reduced photosynthetic ability of plants by combining reduction in chlorophyll contents (Ferguson, 1984).

Table 1. Reduction in chlorophyll content (a, b, total) in the variety due to the infection of root-knot nematode.

\begin{tabular}{|c|c|c|c|c|}
\hline Varieties & Healthy leaf & Infected leaf & Mean & $\begin{array}{l}\text { \% increase }(+) / \text { decrease (-) } \\
\text { over control }\end{array}$ \\
\hline \multicolumn{5}{|c|}{ Chlorophyll 'a' content mg/g leaf } \\
\hline BBSR-19-2-1 (S) & 1.13 & 0.97 & 1.05 & -84.18 \\
\hline BRB-26-1(R) & 0.81 & 0.79 & 0.80 & -2.93 \\
\hline BRB-25-1(S) & 1.24 & 1.05 & 1.14 & -15.27 \\
\hline BRB-7-1(R) & 1.54 & 1.07 & 1.31 & -30.79 \\
\hline $\operatorname{SEM}( \pm)$ & 0.21 & 0.14 & & \\
\hline $\mathrm{CD}(0.05)$ & 0.66 & 0.45 & & \\
\hline \multicolumn{5}{|c|}{ Chlorophyll 'b' content mg/g leaf } \\
\hline BBSR-19-2-1 (S) & 0.32 & 0.32 & 0.32 & -0.928 \\
\hline BRB-26-1(R) & 0.24 & 0.23 & 0.09 & -3.33 \\
\hline BRB-25-1(S) & 0.41 & 0.35 & 0.38 & -14.62 \\
\hline BRB-7-1(R) & 0.82 & 0.38 & 0.60 & -53.75 \\
\hline $\operatorname{SEM}( \pm)$ & 0.07 & 0.05 & & \\
\hline $\mathrm{CD}(0.05)$ & 0.24 & 0.17 & & \\
\hline \multicolumn{5}{|c|}{ Total chlorophyll content $\mathrm{mg} / \mathrm{g}$ leaf } \\
\hline BBSR-19-2-1 (S) & 1.45 & 1.30 & 1.37 & -10.39 \\
\hline BRB-26-1(R) & 1.05 & 1.02 & 2.08 & -2.92 \\
\hline BRB-25-1(S) & 1.66 & 1.41 & 1.53 & -15.16 \\
\hline BRB-7-1(R) & 2.37 & 1.45 & 1.91 & -38.75 \\
\hline $\operatorname{SEM}( \pm)$ & 0.08 & 0.05 & & \\
\hline $\mathrm{CD}(0.05)$ & 0.24 & 0.16 & & \\
\hline
\end{tabular}

\section{Conclusion}

Some selective changes occur in the metabolism either as consequences of the establishment of compatible (susceptible) host-pathogen interactions or as a result of incompatibility (resistant) between host and parasite. During investigation, the decreased chlorophyll content both 'a' , 'b' and total was non-significant in resistant varieties due to alteration of nutrition and physiology of the plans by nematode infection but among the tested varieties maximum decrease in chlorophyll ' $a$ ', 'b' and total in the varieties BBSR-19-2-1(S)( $-84.18 \%)$, BRB$7-1(\mathrm{R}) \quad(-53.75 \%)$ and BRB-7-1(R) (-38.75\%) respectively.

\section{Conflict of interest statement}

Authors declare that they have no conflict of interest.

\section{References}

Ferguson, I.B., 1984. Calcium in plant senescence and fruit ripening, Plant Cell Environ. 7, 477-489.

Melakeberhan, H., Webster, J. M., Brooke, R. C., Dauria, J. M., Cackette, M., 1987. Effects of Meloidogyne incognita on plant nutrient concentration and its influence on the physiology of beans. J. Nematol. 19, 324-330.

Nayak, D. K., 2006. Biochemical evaluation of various metabolites as influenced by root-knot nematode, Meloidogyne incognita in susceptible and resistant brinjal 
cultivars. Ph.D. thesis submitted to the Orissa University of Agriculture and Technology, Bhubaneswar.

Pandey, R. K., Nayak, D. K., Kar, R., 2016. Effects of chlorophyll contents of green gram varieties /lines as influenced by root-knot nematode Meloidogyne incognita. Int. J. Curr. Res. Biosci. Plantbiol. 3(11), 17-22.

Parveen, K., Haseeb, A., Shukla, P. K. I., 2006. Pathogenic potential of Meloidogyne incognita on Mentha arvensis cv. Gomti. Ind. J. Nematol. 36, 177-180.

Poornima, K., Vadivelu, S., 1998. Pathogenisity of Meloidogyne incognita to turmeric (Curcuma longa L.). Proceedings of the 3rd International Symposium of AfroAsian Society of Nematologists, Sugarcane Breeding Institute, Coimbatore, April 16-19, 1998. pp.29-31.

Ramakrishnan, S., Rajendran, G., 1999. Comparison of different methods of control of Meloidogyne incognita in relation to growth and yield of papaya. Nematol. Mediter. 27, 115-118.

Tiyagi, S. A., Alam, M. M., 1990. Effect of root-knot, reniform and stunt nematodes on plant growth, water absorption capability and chlorophyll content on chickpea. Int. Chickpea Newslet. 22, 40-42.

Vaishnav, M. U., Patel, H. R., Dhruj, I. U., 1985. Pathogenicity of Meloidogyne arenaria on Arachis hypogaea, Ind. J. Nematol. 15(2), 235-236.

Vashishth, K., Fazal, M., Imran, M., Raza, M. M. A., Siddiqui, Z. A., 1994. Morphological and biochemical response of blackgram cultivars of Meloidogyne incognita. J. Ann. Plant Prot. Sci. 2, 13-18.

Williamson, V. M., Gleason, C. A., 2003. Plant-nematode interactions. Curr. Opin. Plant Biol. 6(4), 327-333.

\section{How to cite this article:}

Behera, R., Nayak, D.K., Swain, R., 2016. Effects of chlorophyll contents of rice bean varieties/lines as influenced by root-knot nematode, Meloidogyne incognita. Int. J. Curr. Res. Biosci. Plant Biol. 3(12), 49-52. doi: http://dx.doi.org/10.20546/ijcrbp.2016.312.007 